\title{
NEPHROBRONCHIAL FISTULA SECONDARY TO XANTOGRANULOMATOUS PYELONEPHRITIS
}

\author{
JOSE R. DE SOUZA, JULIANA A. ROSA, NEY C. B. BARBOSA \\ Goiânia General Hospital, Goiânia, Goiás, Brazil
}

\begin{abstract}
Introduction: Nephrobronchial fistula is a rare complication of xanthogranulomatous pyelonephritis, a disease that can fistulize to lungs, skin, colon and other organs.

Case Report: A 37-year old patient presented a chronic history of lumbar pain and thoracic symptoms such as cough, dyspnea and oral elimination of pus. Patient went to several services and was submitted to 2 thorax surgeries before definitive treatment (nephrectomy) was indicated. After nephrectomy, the patient presented an immediate improvement with weight gain $(8 \mathrm{~kg} / 1$ month) and all his symptoms disappeared.

Conclusion: This clinical case illustrates the natural history of nephrobronchial fistula, the importance of clinical history for diagnosis and the relevance of early treatment of renal lithiasis.
\end{abstract}

Key words: kidney; xanthogranulomatous pyelonephritis; kidney calculi; urinary fistula; urinary tract infection; bronchial fistula

Int Braz J Urol. 2003; 29: 241-242

\section{INTRODUCTION}

Xanthogranulomatous pyelonephritis is caused by chronic presence of stones in the excretory system, which evolves with localized infection, renal destruction and systemic impairment. Fistulization is a rare complication (1-3). There are reports of nephrobronchial $(1,2)$, nephrocutaneous (2), colonic (3), gastric, jejunal fistulas, and also fistulas to psoas muscle, flank and gluteal region.

\section{CASE REPORT}

VSL, 37 years old, Caucasian, without pathological antecedents. Between 1985 and 1993, the patient presented several crises of renal colic and eliminated 20 calculi. From 1994 to January 1999, he presented a continuous pain in right lumbar region and medicated himself with analgesic drugs. Early in
1999, he presented pyuria, $40^{\circ} \mathrm{C}$ fever, anorexia and renal stones that were treated clinically.

After 3 months, he evolved with dyspnea, being hospitalized several times. In 1999, he sought the General Hospital due to dyspnea, when 1 liter of pus was drained from his right hemithorax and he was subjected to antibiotic therapy.

In July 1999 he presented "pus taste in the mouth", cough and dyspnea. He sought the hospital where thorax was drained and surgically debrided. Fifteen days later, still with a thorax drain, he came back for presenting the initial clinical picture. By the end of July 1999 a right inferior lobectomy was performed, with clinical improvement and release from hospital.

After some months cough returned and there was fistulization with purulent drainage through the right thoracolumbar wall. Output from lumbar fistula decreased progressively as the patient began to expel pus by the mouth until the fistula's closure. 
From 2000 to April 2001 patient expelled pus by the mouth in larger amount during periods of cough, physical efforts and mainly when he flexed the abdomen over his tights. During this period, the patient was assessed by several medical teams. According to him, clinical doctors and urologists thought that the disease was basically renal, but pneumologists disagreed with this hypothesis.

Patient was then seen in General Hospital and, after urologic assessment and right retrograde pyelography (Figure-1), a nephrobronchial fistula was suggested and patient underwent a right nephrectomy with drainage of a subphrenic abscess by mid-2001. He evolved with immediate improvement, ceasing of cough and oral elimination of pus, disappearance of anemia and anorexia, recovering 8 kilograms within 1 month post-operatively. The anatomopathological examination evidenced xanthogranulomatous pyelonephritis.

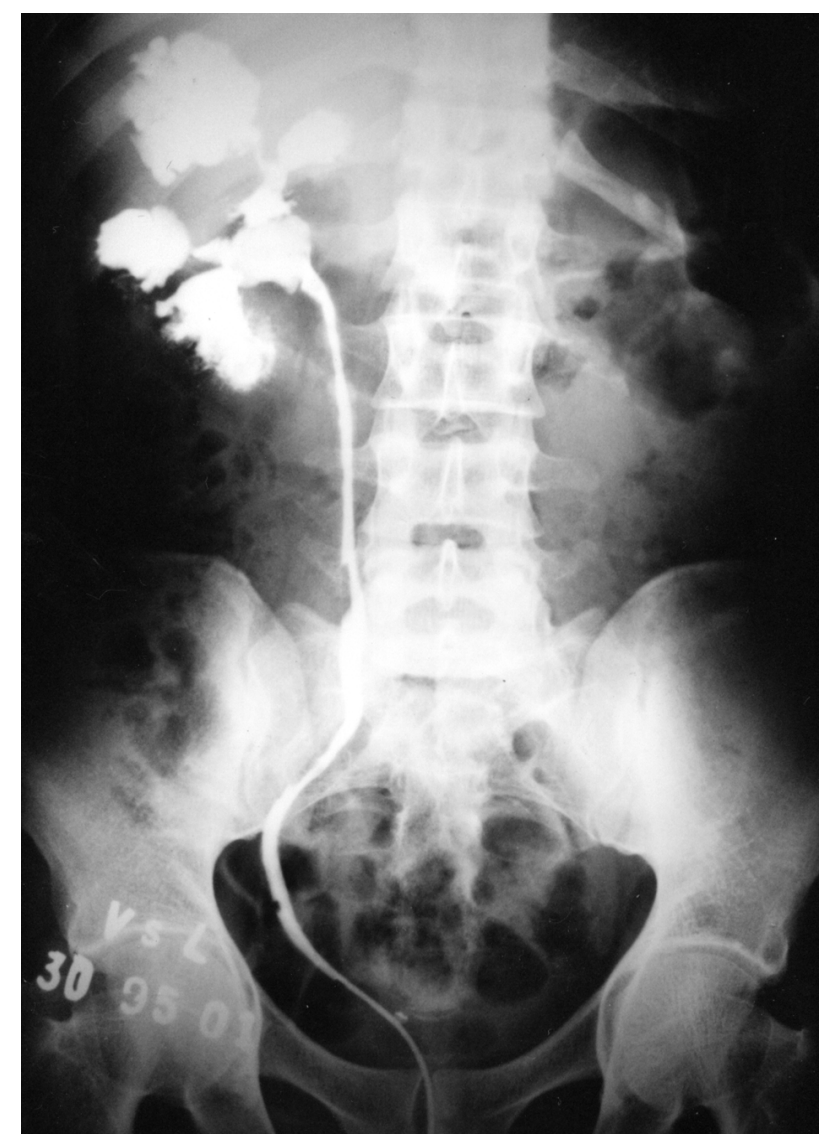

Figure 1 - Right retrograde pyelography with an image of subphrenic abscess and nephrobronchial fistula.

\section{COMMENTS}

Nephrobronchial fistula are rare complications of renal lithiasis that usually occur following a long period of disease. Infection by human immunodeficiency virus, association with diabetes and the presence of untreated renal stones are predisposing factors (1-3).

The patient in this report presented untreated renal stone associated with renal colic, renal cavity infection, thoracocutaneous fistulization, cough, dyspnea, and finally purulent expectoration.

Treatment in advanced cases should be nephrectomy with drainage of the abscess and the fistula (3).

This case illustrates the natural history of nephrobronchial fistula, the significance of clinical history for diagnosis and the relevance of early treatment of renal lithiasis.

\section{REFERENCES}

1. Caberwal D, Katz J, Reid R, Newman HR: A case of nephrobronchial and colonobronchial fistula presenting as lung abscess. J Urol. 1977; 117:371-3.

2. Calvo Quintero JE, Alcover Garcia J, Gutierrez del Pozo R, Pedemonte Vives J, Romero Martin JA, Corominas Estrella $S$, et al.: Fistulization in xanthogranulomatous pyelonephritis. Presentation of 6 clinical cases and review of the literature. Actas Urol Esp. 1989; 13:363-7.

3. Rao MS, Bapna BC, Rajendran LJ, Shrikhande VV, Prasanna A, Subudhi CL, et al.: Operative management problems in nephrobronchial fistula. Urology 1981; 17:362-3.

Received: November 25, 2002 Accepted after revision: April 2, 2003

\footnotetext{
Correspondence address:

Dr. Jose Rosa de Souza

Hospital do Rim de Goiânia

Alameda das Rosas, 2041

Goiânia,GO, 74125-010, Brazil

Fax: + 5562 291-2030

E-mail: joserosasouza@aol.com
} 